\title{
PENERAPAN PRINSIP NATURE IN THE SPACE DAN NATURE OF THE SPACE PADA HEALTHY PLAZA AVENUE DI KOTA BARU PARAHYANGAN
}

\author{
Rizal Pardamean Sihite ${ }^{1}$, Nurtati Soewarno ${ }^{2}$ \\ ${ }^{1}$ Mahasiswa, Prodi Arsitektur, Fakultas Arsitektur dan Desain, Institut Teknologi Nasional Bandung. \\ rizalperdamean@mhs.itenas.ac.id \\ ${ }^{2}$ Prodi Arsitektur, Fakultas Arsitektur dan Desain, Institut Teknologi Nasional Bandung
}

Naskah diajukan pada: 4 Agustus 2021

Naskah revisi akhir diterima pada: 7 September 2021

\begin{abstract}
Abstrak
Manusia pada hakikatnya tidak bisa dipisahkan dengan alam karena manusia sangat bergantung pada alam untuk kelangsungan hidupnya. Saat ini memasukan unsur alam pada rancangan sebuah bangunan sudah menjadi gaya hidup dan menjadi trend, seperti terlihat pada beberapa bangunan komersial, seperti Hotel, Shopping Mall yang mengambil tema alam. Healthy Plaza Avenue adalah sebuah pusat perbelanjaan yang direncanakan dengan tujuan memenuhi fasilitas di Kota Baru Parahyangan, sebuah lingkungan hunian baru yang mempunyai visi kota hijau yang mandiri. Metode perancangan Healthy Plaza Avenue dimulai dari perumusan masalah, pengumpulan data, proses desain dan produk rancangan. Nature in the space dan Nature of the space merupakan dua dari ketiga kategori prinsip desain biofilik yang dinilai akan sesuai diterapkan pada perancangan Healthy Plaza Avenue. Aplikasi dari prinsip Nature in the space dan Nature of the space terlihat pada Atrium dengan menempatkan tanaman hias dan pohon peneduh yang dilengkapi saluran air yang bermuara di Event Plaza. Sedangkan pada area luar direncanakan Rain Garden yang berfungsi selain untuk menambah keindahan juga sebagai area resapan dan daur ulang air untuk kebutuhan bangunan. Selain itu ditempatkan pula tanaman gantung pada façade bangunan untuk mempertegas unsur hijau sehingga Healthy Plaza Avenue dapat harmonis dengan lingkungannya. Diharapkan konsep Nature in the Space and Nature of the Space dapat sejalan dengan visi Kota Baru Parahyangan sebagai sebuah kota mandiri yang mempertahankan keasrian lingkungannya.
\end{abstract}

Kata-kata Kunci: Nature in The Space dan Nature of The Space, Biofilik, Shopping Mall, Kota Baru Parahyangan

\begin{abstract}
Humans are essential can not be separated from nature because humans rely heavily on nature for their survival. Currently including natural elements in the design of a building has become a lifestyle and trend, as seen in some commercial buildings, such as Hotels, Shopping Malls that take the theme of nature. Healthy Plaza Avenue is a planned shopping center to fulfill facilities in Kota Baru Parahyangan, a new residential neighborhood that has a vision of an independent green city. Healthy Plaza Avenue design method starts from problem formulation, data collection, design process, and design products. Nature in the space and Nature of the space are two of the three categories of biophilic design principles that are considered to be appropriately applied to the design of Healthy Plaza Avenue. The application of the principles of Nature in the space and nature of the space is seen in the Atrium by placing ornamental plants and shade trees equipped with waterways that boil in the Event Plaza. While in the outside area is a planned Rain Garden that serves in addition to adding beauty also as a catchment and recycling area for the needs of the building. In addition, hanging plants are also placed on the façade of the building to reflect the green elements so that Healthy Plaza Avenue can be harmonious with the environment. It is hoped that the concept of Nature in the Space and Nature of the Space can be in line with the vision of Kota Baru Parahyangan as an independent city that maintains its environmental beauty.
\end{abstract}

Keywords: Nature in The Space and Nature of The Space, Biophilic, Shopping Mall, Kota Baru Parahyangan 


\section{Pendahuluan}

Pesatnya perkembangan kota-kota besar di Indonesia mengakibatkan pembangunan di kawasan sekitar kota, demikian pula dengan kota Bandung yang mengembangkan diri menjadi Bandung Raya. Kota Baru Parahyangan merupakan sebuah lingkungan hunian baru di bagian barat kota Bandung yang masuk kedalam wilayah Bandung Raya. Kawasan ini bermula dari area perkebunan sehingga konsep hijau yang diterapkan untuk kawasan ini dinilai tepat. Ruang-ruang hijau di kawasan ini dipertahankan dan ruang hijau tambahan direncanakan dengan baik sehingga Kota Baru Parahyangan menjadi sebuah lingkungan hunian yang asri.

Healthy Plaza Avenue adalah sebuah pusat perbelanjaan yang direncanakan dengan tujuan untuk memenuhi fasilitas pelengkap di Kota Baru Parahyangan. Pusat perbelanjaan ini menerapkan konsep biofilik Nature in the Space dan Nature of the Space yang diharapkan dapat memberikan manfaat bagi kesejahteraan manusia, baik secara psikologis maupun fisiologis dengan pendekatan seperti di alam, seperti yang diungkapkan oleh Priatman (2012).

Penerapan konsep Nature in the Space and Nature of the Space pada pusat perbelanjaan ini terutama diterapkan pada ruang dalam dengan menambahkan unsur alam seperti tanaman hidup dan air. Hal ini terlihat pada area Atrium yang dilengkapi taman dengan beberapa pohon peneduh dan tanaman hias serta saluran air yang bermuara hingga ke Event Plaza di area luar.

Adapun pada ruang luar konsep ini diterapkan dengan tidak melakukan perkerasan yang berlebihan, perkerasan direncanakan hanya pada pedestrian ways dan jalan masuk kendaraan sedangkan parkir kendaraan direncanakan pada basement. Tanaman di bagian luar tidak hanya sebagai unsur estetika tetapi digunakan pula sebagai area resapan, berupa rain Garden untuk meresapkan air hujan sekaligus menyaring air hujan yang akan digunakan kembali untuk kebutuhan pada bangunan.

Dengan penerapan konsep Nature in the Space and Nature of the Space diharapkan sambil berbelanja pengunjung dapat berinteraksi dengan alam dan diharapkan pula Healthy Plaza Avenue dapat menjadi sebuah pusat perbelanjaan yang selaras dengan visi Kota Baru Parahyangan sebagai sebuah Kota Hijau yang mandiri di Bandung Raya.

\section{Kajian Pustaka}

Pusat perbelanjaan modern Shopping Mall adalah tempat perbelanjaan berupa Department Store besar sebagai daya tarik untuk toko - toko kecil ataupun rumah makan. Tipologi toko itu diantaranya dengan menghadap ke koridor sebagai pusat sirkulasi pengunjung Department Store tersebut, seperti yang diungkapkan Maitland (1985) yang dikutip dari Savitri (2018). Dengan begitu didapatkan interaksi antara pengunjung dan pembeli di dalam sebuah pusat perbelanjaan.

Menurut Browning et al., (2014), Arsitektur Biofilik merupakan sebuah teori dengan prinsip dan tujuan untuk mendapatkan hubungan antara lingkungan hidup (alam), manusia, dan arsitektur. Konsep tersebut bertujuan untuk meningkatkan kesejahteraan secara mental dan kualitas hidup penggunanya. Dengan memadukan unsur alam dengan arsitektur, baik itu dengan penerapan bahan alam maupun bentuk-bentuk alami ke dalam desain. Selain itu biofilik bertujuan untuk memasukkan pemahaman 'biofilia' ke dalam objek rancangan, sehingga manusia dan alam akan saling berinteraksi di dalam bangunan dan lanskap, seperti yang diungkapkan Kellert et al., (2009) yang dikutip dari Sumartono (2015).

Menurut Almused (2011) Biofilik dapat menciptakan ruang yang restorative untuk menyehatkan sistem saraf dan menampilkan suatu lingkungan yang estetik. Hal itu meliputi kebutuhan fisiologis berupa ketenangan manusia melalui pendekatan bioklimatik, sedangkan untuk psikologis berupa kesehatan manusia melalui desain biofilik. Desain biofilik ini dapat diimplementasikan secara buatan atau alami, dan bisa diterapkan melalui elemen-elemen interior maupun eksterior. 
Biofilik memiliki prinsip sebagai acuan ketentuan desain yang akan dirancang. Menurut Browning, yang dikutip dari Soderlund (2019), prinsip biofilik mempunyai 14 pola desain yang terbagi menjadi tiga kategori yaitu, Nature in the Space, Natural Analogues, dan Nature of the Space untuk mengakomodir perancangan di perkotaan. Prinsip tersebut ditunjukan pada Tabel 1.

Tabel 1. 14 Pola Prinsip desain biofilik

\begin{tabular}{|c|c|c|}
\hline $\begin{array}{l}\text { Nature in } \\
\text { The Space }\end{array}$ & $\begin{array}{c}\text { Natural } \\
\text { Analogues }\end{array}$ & $\begin{array}{l}\text { Nature in } \\
\text { The Space }\end{array}$ \\
\hline $\begin{array}{l}\text { P1. Visual connection with } \\
\text { Nature - Pemandangan } \\
\text { terhadap unsur alam, sistem } \\
\text { kehidupan, dan proses alam }\end{array}$ & $\begin{array}{l}\text { P8. Biomorphic forms \& } \\
\text { Patterns - Acuan yang } \\
\text { mempunyai kontur, pola, } \\
\text { tekstur atau susunan rangka } \\
\text { seperti pada alam }\end{array}$ & $\begin{array}{l}\text { P11. Prospect - Adanya } \\
\text { pemadangan luas, adanya } \\
\text { balkon, dan ruang terbuka }\end{array}$ \\
\hline $\begin{array}{l}\text { P2. Non-visual connection } \\
\text { with nature - Rangsangan } \\
\text { terhadap pendengaran, peraba, } \\
\text { dan penciuman }\end{array}$ & $\begin{array}{l}\text { P9. Material connection with } \\
\text { nature - Material alami susuai } \\
\text { dengan lingkungan lokal }\end{array}$ & $\begin{array}{l}\text { P12. Refuge - Adanya ruang } \\
\text { lindung, adanya kanopi atau } \\
\text { plafond yang tinggi dan zona } \\
\text { private }\end{array}$ \\
\hline $\begin{array}{l}\text { P3. Non-ryhthmic sensory } \\
\text { Stimuli - Hubungan samar } \\
\text { dengan alam }\end{array}$ & $\begin{array}{l}\text { P10. Complexity \& Order - } \\
\text { Kompleksitas dan aturan }\end{array}$ & $\begin{array}{l}\text { P13. Mystery - Adanya } \\
\text { permainan pola yang } \\
\text { misterius, sehingga seseorang } \\
\text { penasaran }\end{array}$ \\
\hline $\begin{array}{l}\text { P4. Thermal \& airflow } \\
\text { Variabillty - Suhu permukaan } \\
\text { yang meniru lingkungan alam }\end{array}$ & & $\begin{array}{l}\text { P14. Risk/peril - Adanya } \\
\text { hubungan lantai dengan } \\
\text { plafond, air mengalir, dan } \\
\text { jembatan }\end{array}$ \\
\hline \multicolumn{3}{|l|}{$\begin{array}{l}\text { P5. Presence of water - } \\
\text { Pengalaman ruang dengan cara } \\
\text { melihat, mendengar, atau } \\
\text { menyentuh air }\end{array}$} \\
\hline \multicolumn{3}{|l|}{$\begin{array}{l}\text { P6. Dynamic \& diffuce light } \text { - } \\
\text { Intensitas cahaya dan bayangan } \\
\text { dapat berubah seiring waktu } \\
\text { seperti yang terjadi pada alam }\end{array}$} \\
\hline $\begin{array}{l}\text { P7. Connection with natural } \\
\text { Systems - Perubahan musiman } \\
\text { yang merupakan ciri ekosistem } \\
\text { yang sehat }\end{array}$ & & \\
\hline
\end{tabular}

Healthy Plaza Avenue menerapkan dua kategori dari prinsip desain biofilik, yaitu Nature in the Space dan Nature of the Space dalam rancangannya. Nature in the space adalah penerapan fisik seperti tanaman hidup, air, binatang, hembusan angin, suara, dan elemen alam lainnya. Penerapan elemen tersebut dapat dicapai melalui ciptaan. Sedangkan Nature of the space adalah cara manusia merespon alam secara psikologis dan pola sifat dalam ruang.

\section{Metode}

Metode yang digunakan dalam rancangan Healthy Plaza Avenue terdiri dari perumusan masalah dan tujuan, pengumpulan data, pengolahan data, proses desain, hingga produk rancangan.

1. Perancangan dimulai dari perumusan masalah yaitu mengumpulkan permasalahan/isu dan tujuan dalam perancangan. 
2. Tahapan selanjutnya dengan pengumpulan data yang terdiri dari data primer dan data skunder. Data Primer berisi pengumpulan data eksisting pada site dan analisis site disekitar Kawasan Kota Baru Parahyangan. Analisis site mempertimbangkan masalah dan potensi yang ada pada lokasi dimana Healthy Plaza Avenue akan direncanakan. Adapun output dari data primer berupa regulasi dan foto-foto keadaan site. Data Sekunder Berisi pengumpulan data melalui studi literatur terkait dengan tema biofilik dari media cetak seperti buku, dan jurnal-jurnal elektronik. Data-data yang diperoleh berupa kajian tentang shopping mall, studi preseden kasus yang berkaitan dengan tema biofilik, studi kelayakan dan regulasi.

3. Data-data primer dan sekunder yang telah terkumpul selanjutnya diolah dalam planning programming sehingga diperoleh konsep yang sesuai dengan perancangan.

4. Setelah melakukan pengolahan data, diperoleh solusi yang akan dirancang, selanjutnya dilakukan proses desain secara rinci, meliputi konsep tapak pada bangunan, konsep massa, konsep ruang dalam, konsep utilitas dan struktur, serta skematik desain.

5. Proses desain yang telah didapat, selanjutnya digunakan untuk melengkapi produk rancangan yang berupa gambar rancangan, laporan, poster hingga animasi.

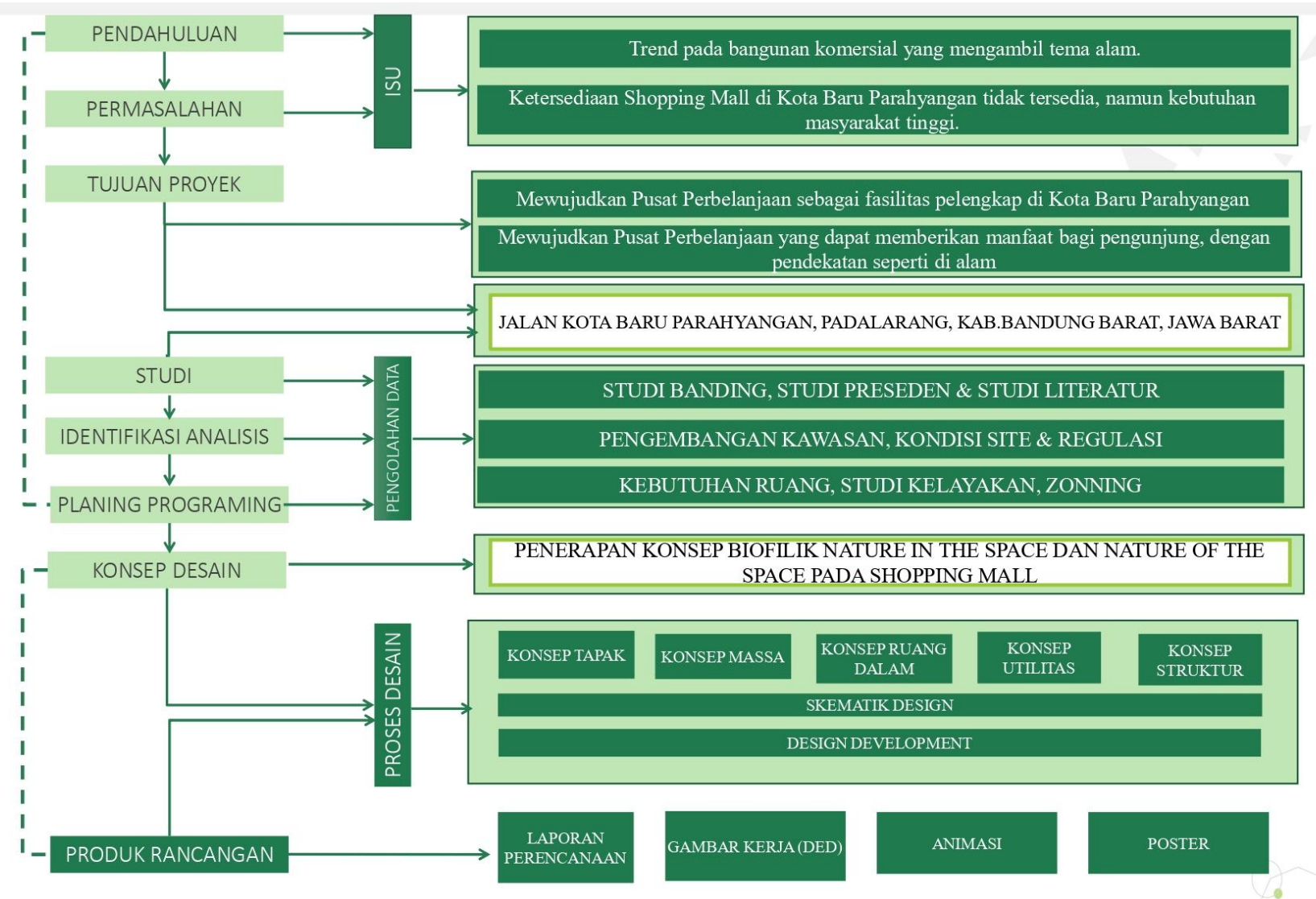

Gambar 1. Metode Skema Pemikiran

Sumber: Penulis, 2021

\section{Hasil dan Pembahasan}

Tapak berlokasi di Kawasan Kota Baru Parahyangan, tepatnya di Jalan Parahyangan Row, Padalarang, Kabupaten Bandung Barat dengan luas lahan 31.300 m2. Lokasi tapak ditunjukan pada Gambar 2. 


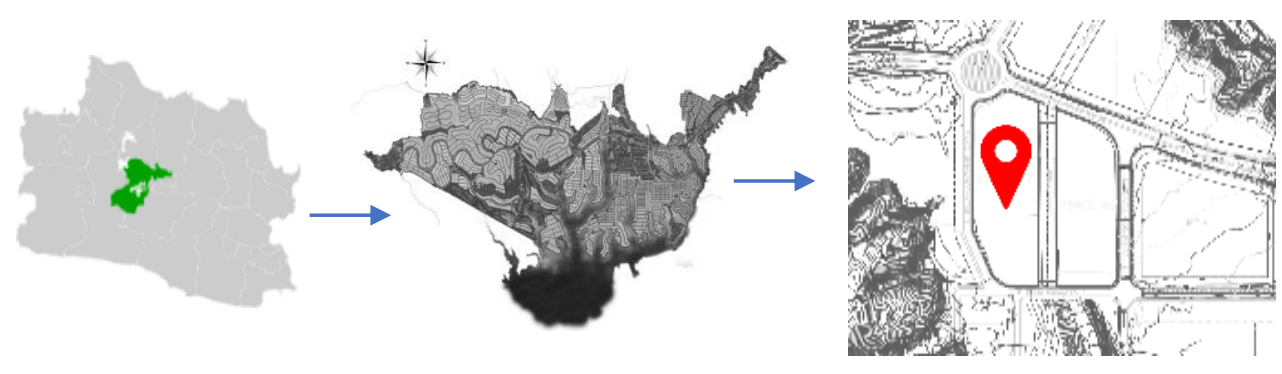

Gambar 2. Lokasi Tapak

Sumber: https://kotabaruparahyangan.com/area-komersial

\section{Konsep Gubahan Massa}

Konsep gubahan massa merupakan analisis tapak yang bertujuan untuk mencari berbagai masalah dan potensi di dalam tapak yang akan dirancang. Hasil analisis dapat menjadi solusi pada konsep desain awal. Proses transformasi gubahan massa yang ditunjukan pada Gambar 3.

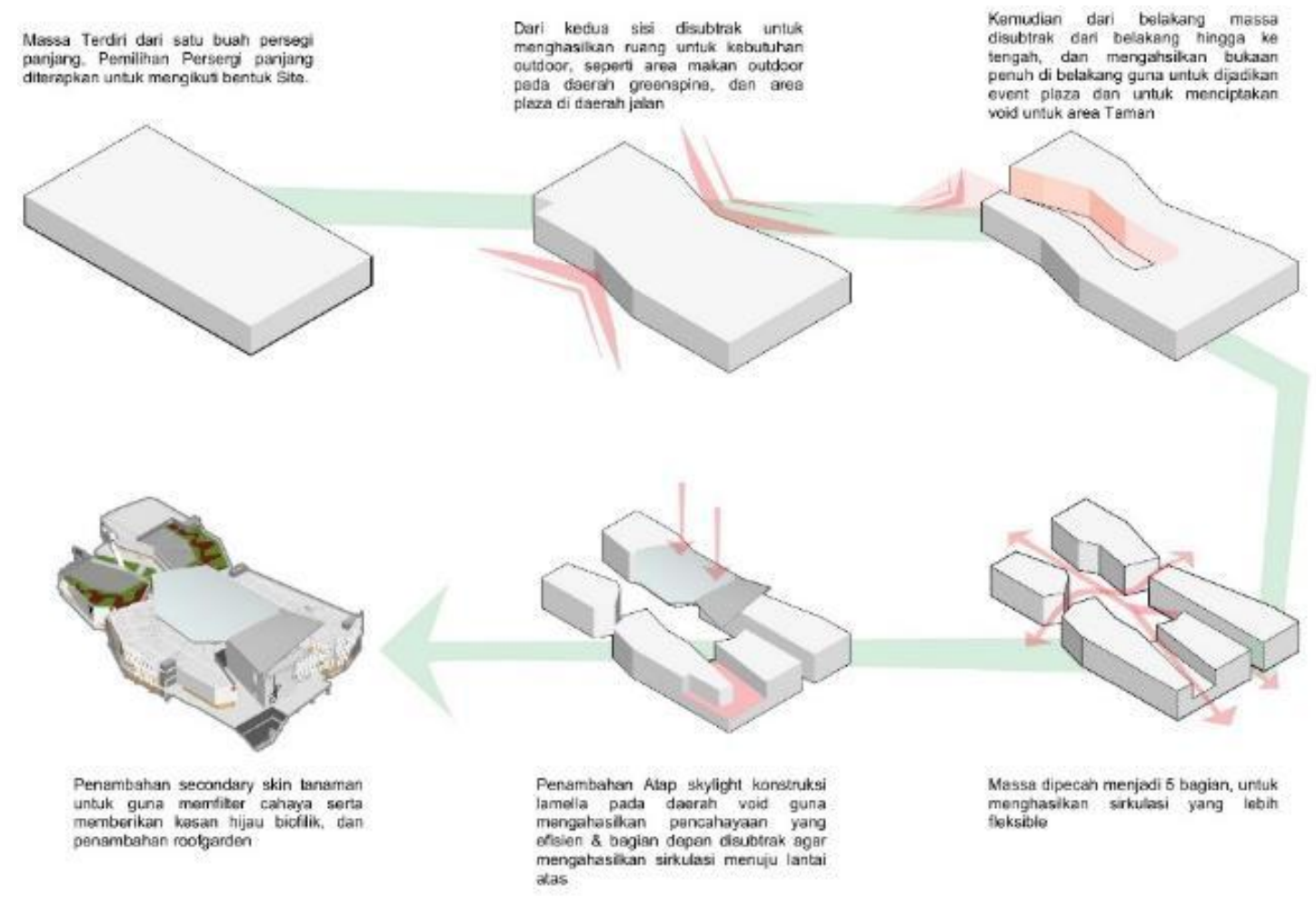

Gambar 3. Konsep Gubahan Massa

Sumber: Penulis, 2021

Hasil dari gubahan massa tersebut menggunakan material yang didominasi oleh baja, beton sebagai struktur maupun fasad, Glass Reinforced Concrete sebagai bahan secondary skin, kayu ulin sebagai area jalan pada area taman didalam maupun diluar, kaca tempered synergi untuk bahan material skylight dan Roof garden.Konsep material bangunan diperlihatkan pada Gambar 4. 


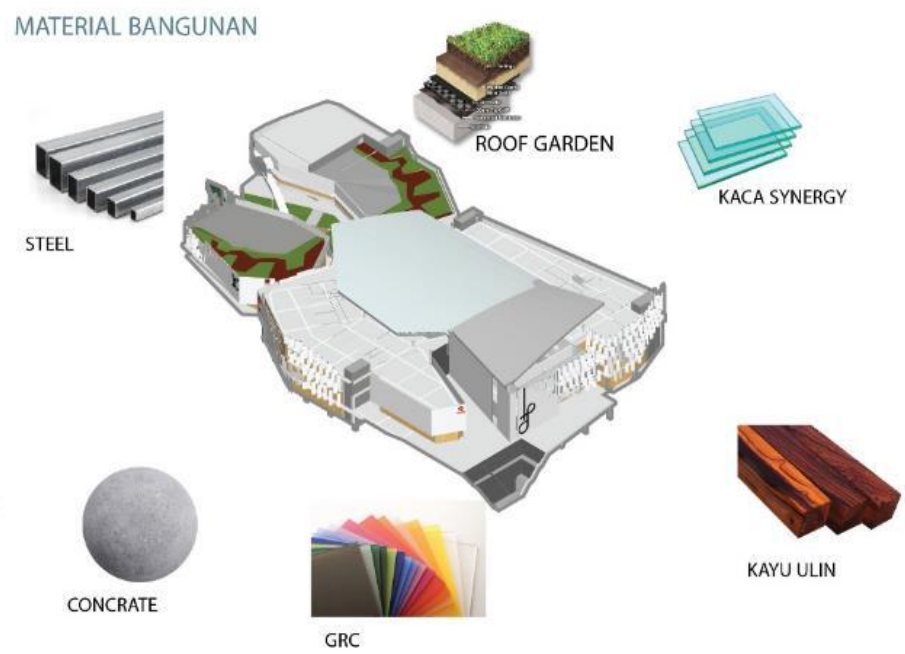

Gambar 4. Material yang Digunakam Pada Bangunan

Sumber: Penulis, 2021

\section{Pembagian Zona Dalam Tapak}

Zonasi pada Healthy Plaza Avenue dibagi menjadi tiga zona, yakni zona publik, semi-publik, dan zona servis. Zona publik terdiri dari Main Gate, Drop-off area, Main Plaza, Event Plaza, Exit Barat Site, Entrance Basement, Exit Basement, dan Green Spine, seperti terlihat pada Gambar 5 di bawah ini.
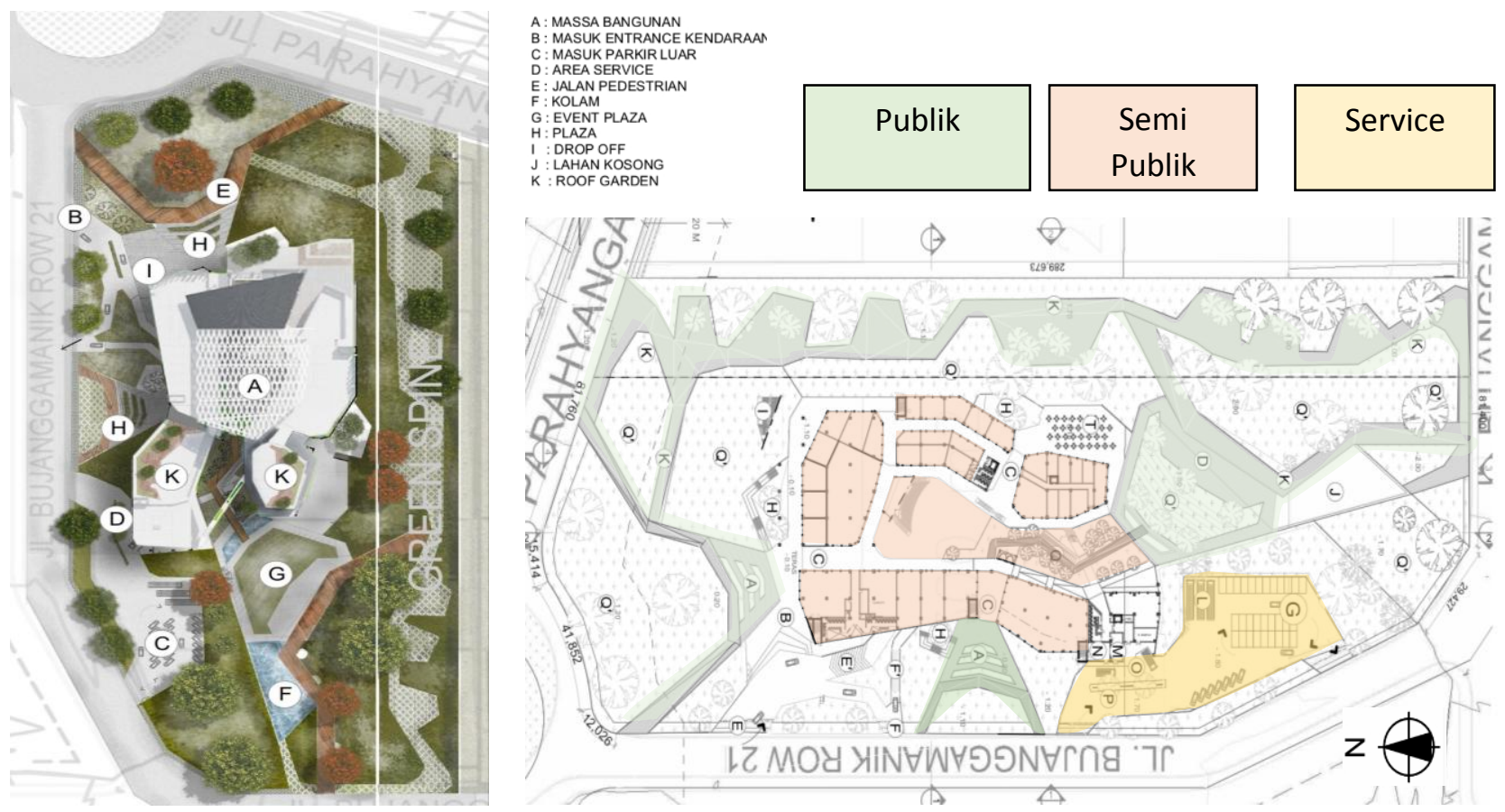

Gambar 5. Gambar Block Plan (kiri) dan Site Plan (kanan)

Sumber: Penulis, 2021

\section{Konsep dan Rancangan Khusus Terkait Tema Perancangan}

Penerapan prinsip Nature in the space dan Nature of the space dalam rancangan, berupa: 


\section{A. Konsep Taman Pada Atrium}

Konsep taman di area atrium diterapkan beberapa prinsip biofilik yang diantaranya:

- P11. Risk/Peril dan P.10 Mystery: Pada sirkulasi air dari reservoir atas menuju river casade yaitu berupa permainan air. Air ini mengalir hingga reservoir bawah, setelah itu dipompa kembali oleh mesin pompa ke basement menuju surge tank. Surge tank berfungsi agar pada saluran air tidak terjadi ledakan pada mesin atau water hammer. Setelah air kembali dialirkan ke reservoir atas. Air yang mengalir di area atrium ini dapat diatur oleh Heat exchanger dengan temperatur yang bisa disesuaikan, seperti yang terlihat pada Gambar 6 dibawah ini.

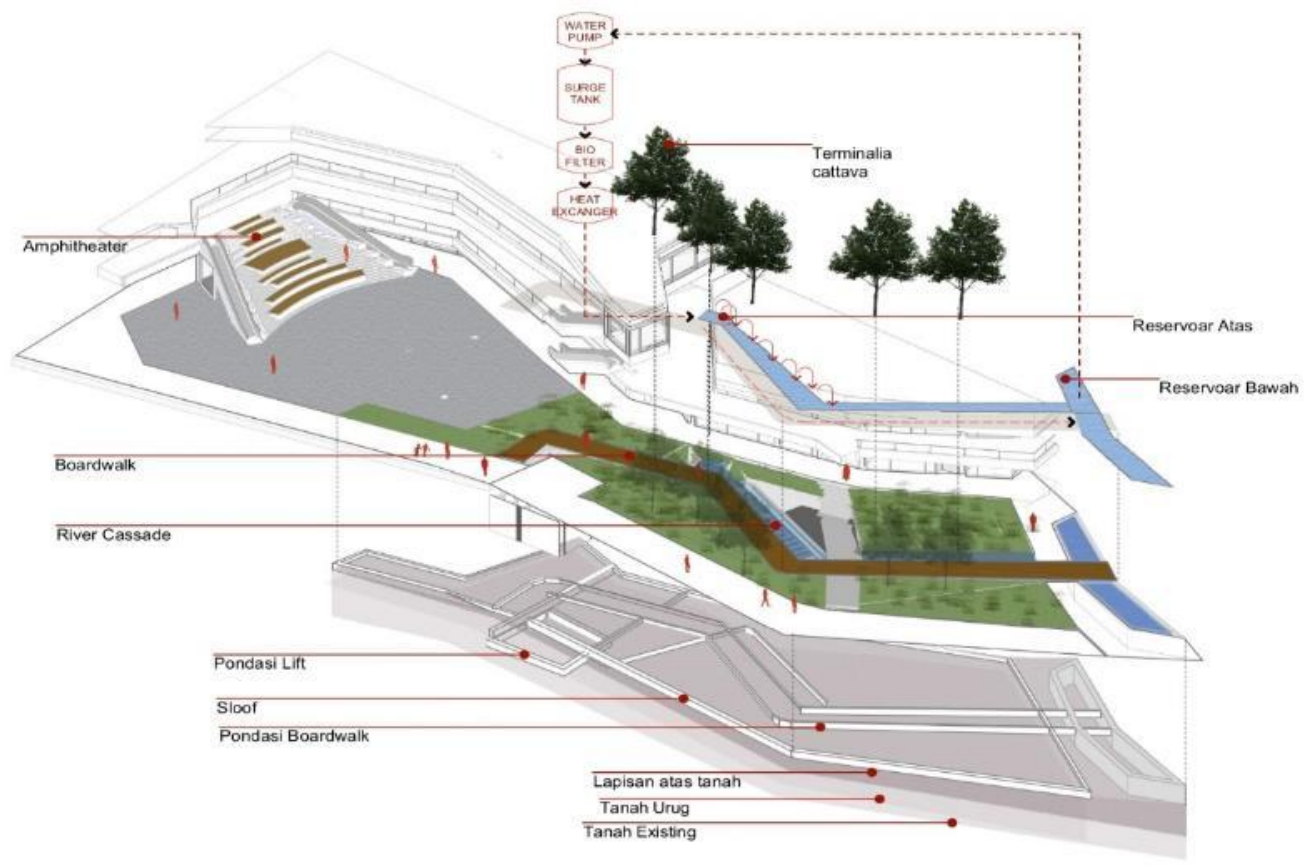

Gambar 6. Konsep Taman Atrium

Sumber: Penulis, 2021

- P1. Visual connection with nature dan P8. Prospect: Area atrium dilengkapi dengan Amphitheater untuk pengunjung yang ingin menyaksikan pertunjukan. Taman dijadikan sebagai background untuk menegaskan konsep alami dari bangunan, seperti pada Gambar 7 di bawah ini.

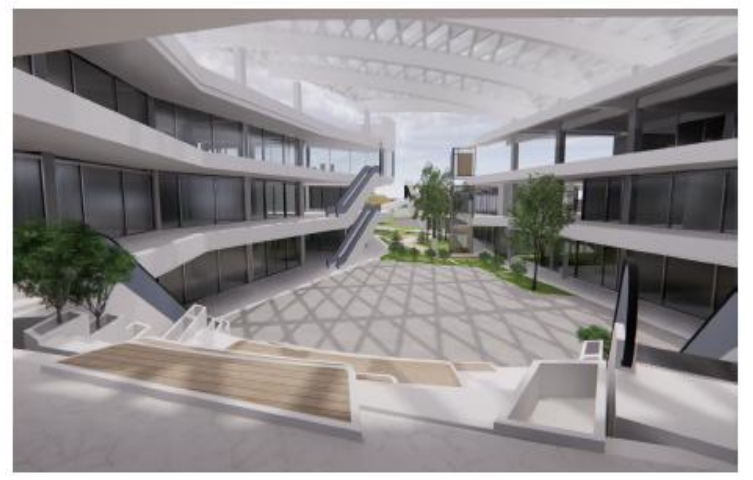

Gambar 7. Perspektif Interior pada Amphitheater

Sumber: Penulis, 2021 
- P2. Non-Visual connection with nature dan P7. Connection with Natural Systems : Atrium dipenuhi tanaman Terminala Catappa, yang berfungsi sebagai pohon peneduh. Selain itu ditanam pula Asteraceae yang dapat mengundang kupu-kupu, serta Lagerstroema, sebagai penghasil wangi - wangian. Ilustrasi taman terlihat pada Gambar 8 dibawah ini.

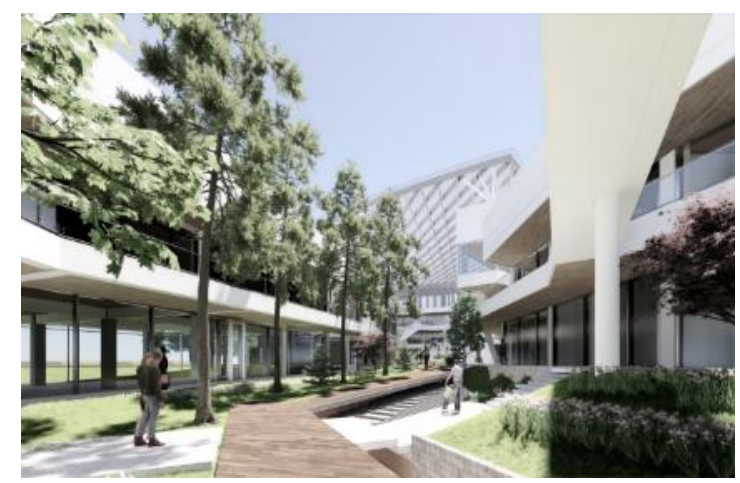

Gambar 8. Perspektif Suasana Taman Atrium Sumber: Penulis, 2021

- P5. Present of Water: Walkway di area taman direncanakan menggunakan dari kayu ulin. Walkway dapat menjadi koridor bagi pengunjung yang ingin menikmati taman. Selain itu disetiap sisinya terdapat saluran air, seperti terlihat pada Gambar 9 di bawah ini.

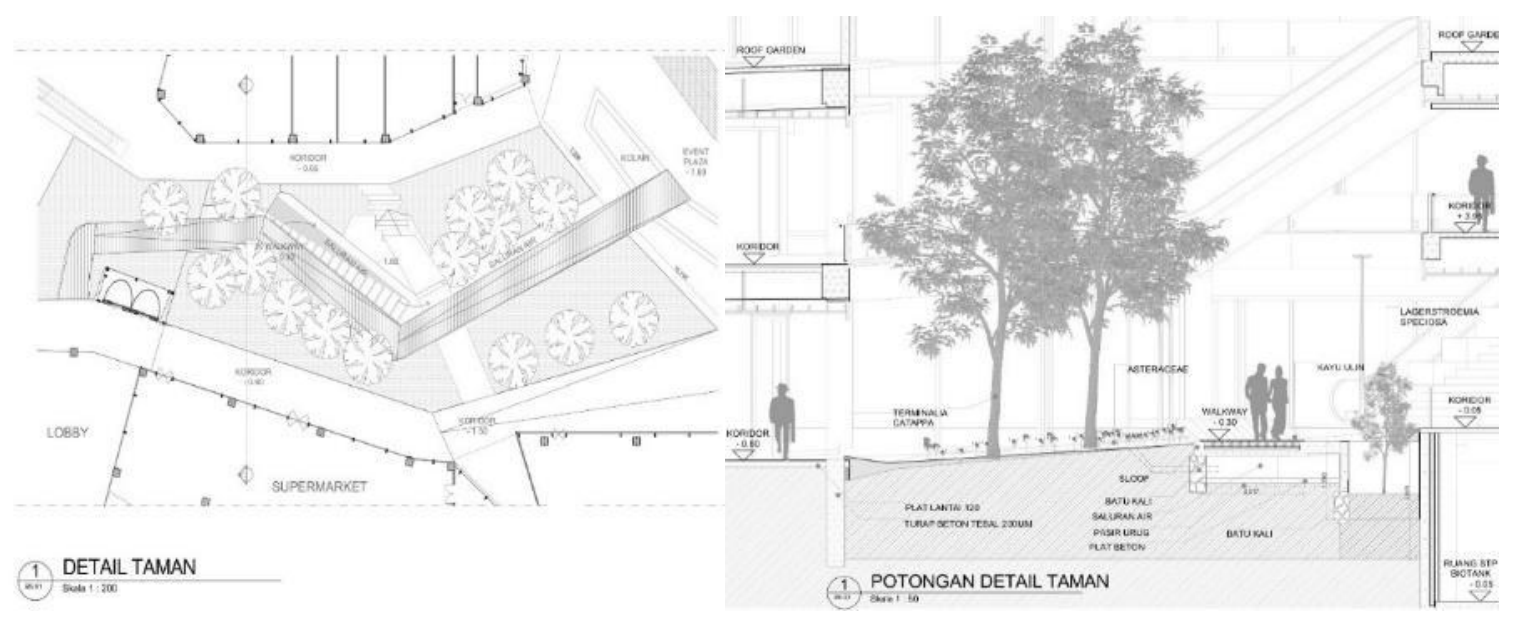

Gambar 9. Detail Taman Atrium

Sumber: Penulis, 2021

\section{B. Konsep Waste Water Management}

Waste Water Management atau sistem daur ulang air merupakan konsep yang diterapkan pada bangunan shopping mall ini, seperti pada Gambar 10.

- P5. Present of Water: Air hujan diserap oleh rain garden kemudian ditampung sementara di detention tank, lalu didistribusi menuju recycled water tank, dan dialirkan sebagai air bersih untuk kebutuhan irigasi taman.

Wastewater management, air buangan dari sanitasi akan dialirkan menuju Sewage Treatment Plant bio tank, lalu dialirkan menuju Waste Water Treatment Plant, kemudian disalurkan menuju natural treatment untuk dilakukan filtrasi. Setelah filtrasi air didistribusikan menuju recycled water tank, dan dialirkan untuk kebutuhan sanitasi, atau untuk irigasi taman. 


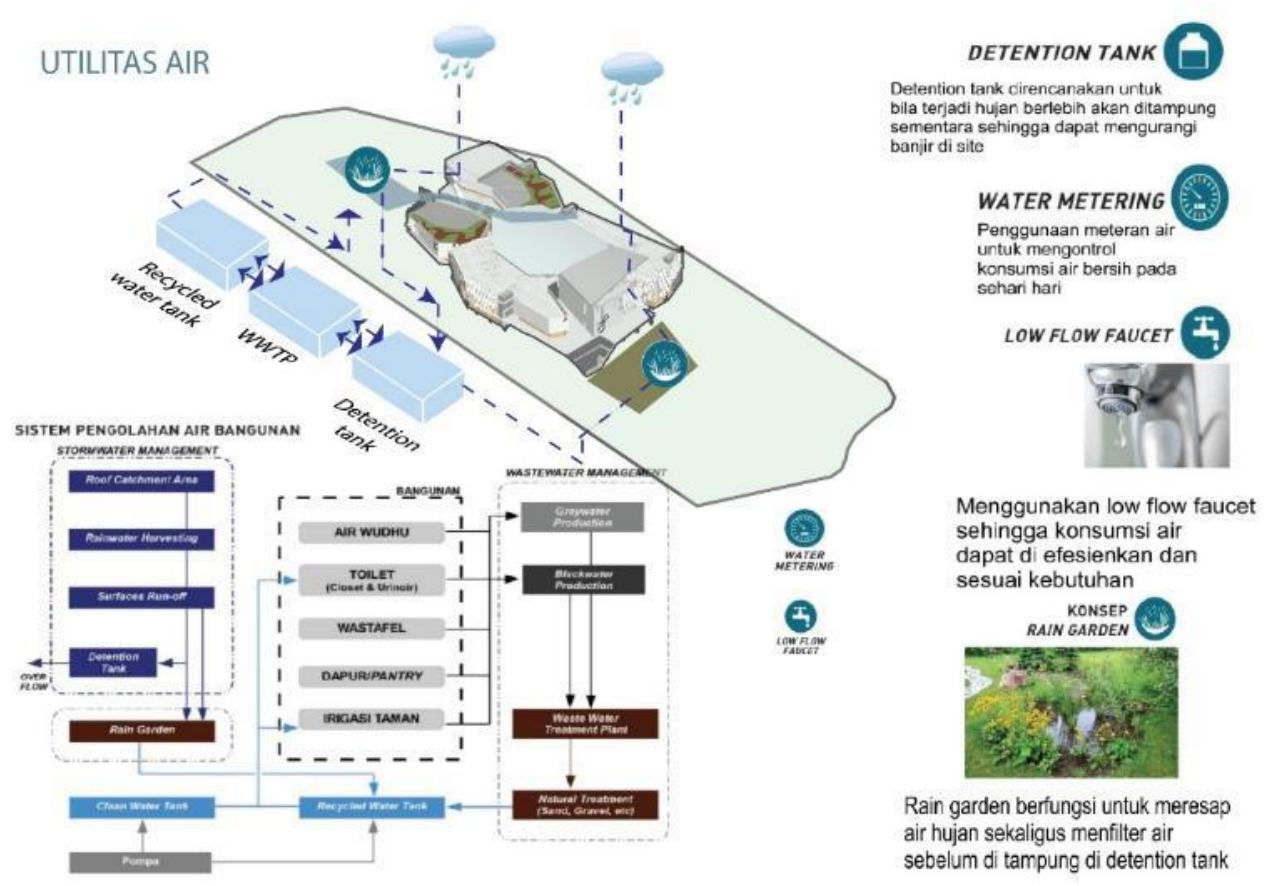

Gambar 10. Konsep Waste Water Management

Sumber: Penulis, 2021

\section{Skylight}

Penggunaan atap skylight dinilai dapat mengurangi pemakaian listrik pada siang hari.

- P6. Dynamic and Diffuse Light: Penggunaan skylight juga dapat mengoptimalkan cahaya pada ruang. Struktur atap menggunakan rangka Lamella dengan material baja, yang diberikan penghubung spider glass untuk menopang tempered glass seperti terlihat pada Gambar 11.
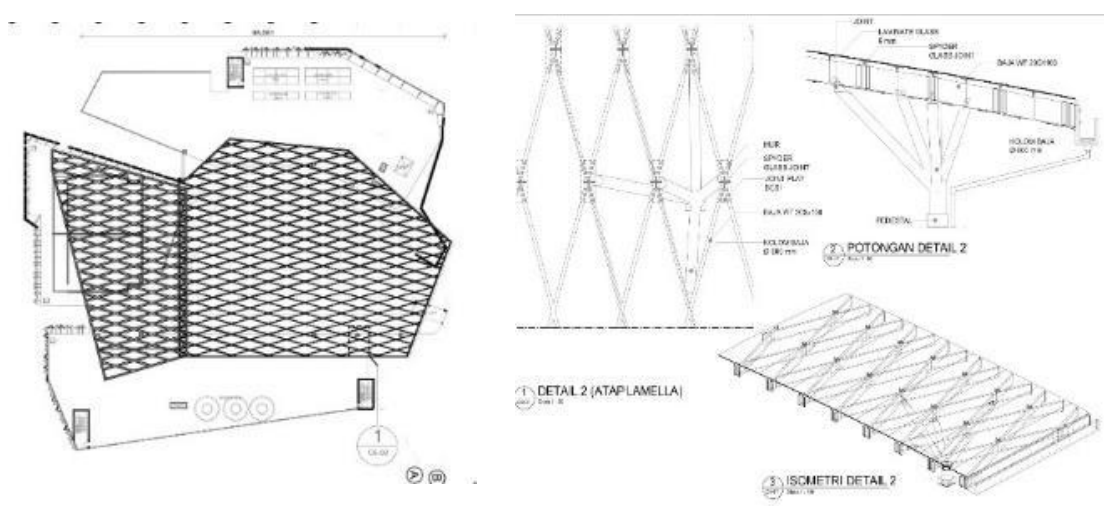

Gambar 11. Detail Atap Lamella

Sumber: Penulis, 2021

- P4. Access to Thermal and Airflow Variability: Potongan atap skylight sengaja diberikan gap antara pedestal baja atap beton agar terjadi cross ventilation untuk udara, sehingga pada daerah atrium terjadi pergantian udara secara alami, hal tersebut dinilai akan mengurangi pemakaian pendingin udara buatan (AC) secara berlebihan, bisa dilihat pada Gambar 12. 


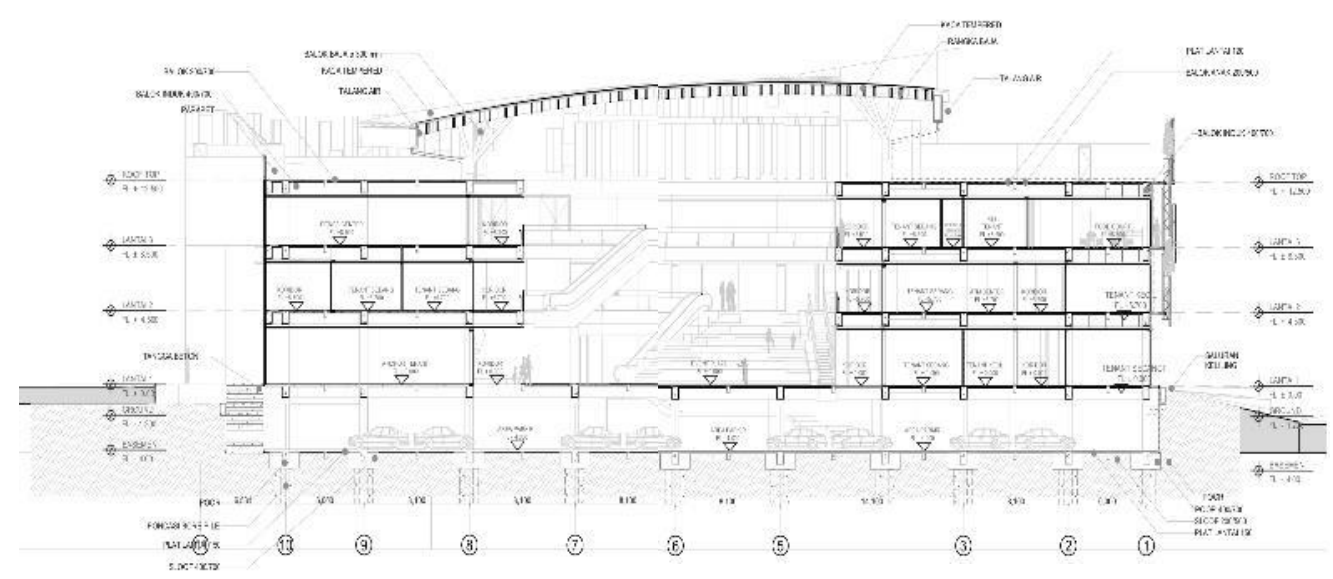

Gambar 12. Potongan Melintang

Sumber: Penulis, 2021

\section{Fasad Vertical Garden}

Fasad Healthy Plaza Avenue ditutup secondary skin yang didominasi oleh vertical garden dengan material Glass Reinforced Concrete.

- P10. Mystery : Fasad bangunan didominasi oleh Glass Reinforced Concrete bergradasi, guna menangkal sinar matahari terik agar tidak terlalu masuk, seperti terlihat pada Gambar 13 dan Gambar 14 dibawah ini.

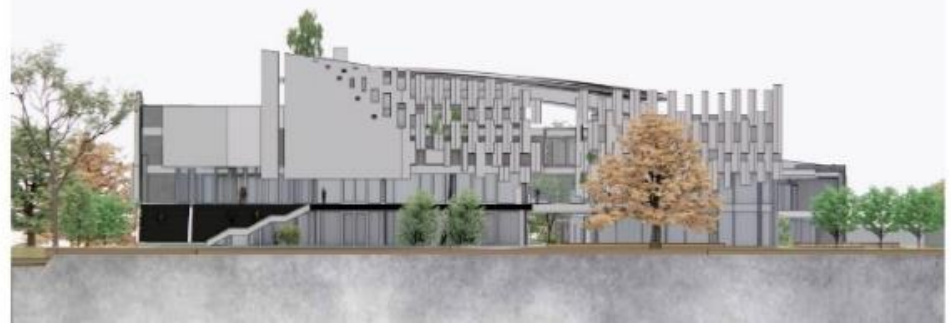

Gambar 13. Tampak Depan (Utara)

Sumber: Penulis, 2021

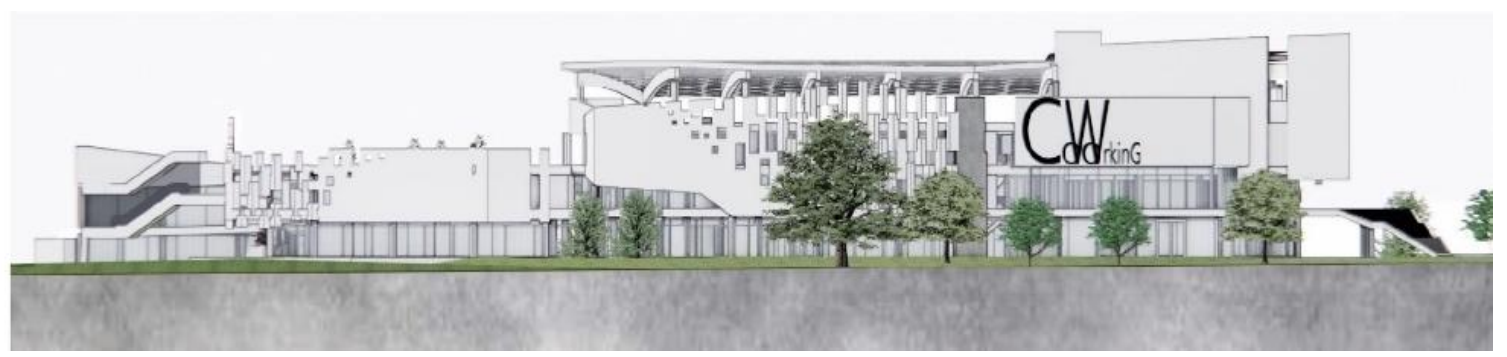

Gambar 14. Tampak Samping (Timur)

Sumber: Penulis, 2021

- P5. Present of Water: Fasad ditanami oleh vertical garden dengan tanaman livistona berupa vertical garden. Sistem penyiraman tanaman dilakukan secara otomatis menggunakan Water Supply Pipe. Sistem ini menggunakan air dari distribusi Waste Water Management. Detail fasad ditunjukan pada Gambar 15. 

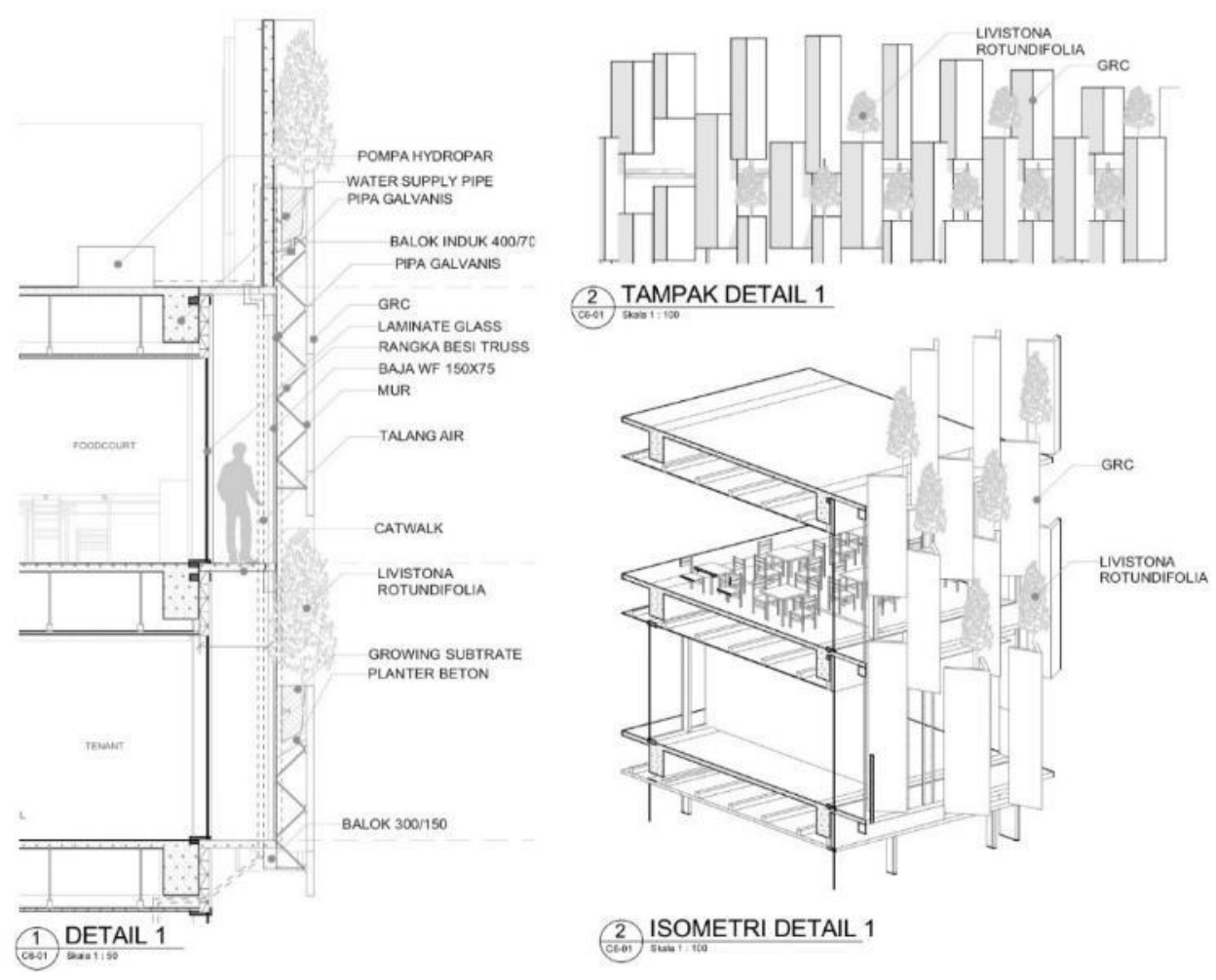

Gambar 15. Detail Fasade

Sumber: Penulis, 2021

- P1. Visual Connection with Nature: Pada Gambar 16 memperlihatkan suasana exterior pada main entrance dan Event Plaza. Vertical garden dinilai memberikan kesan menyatu dengan lingkungan asri Kota Baru Parahyangan.

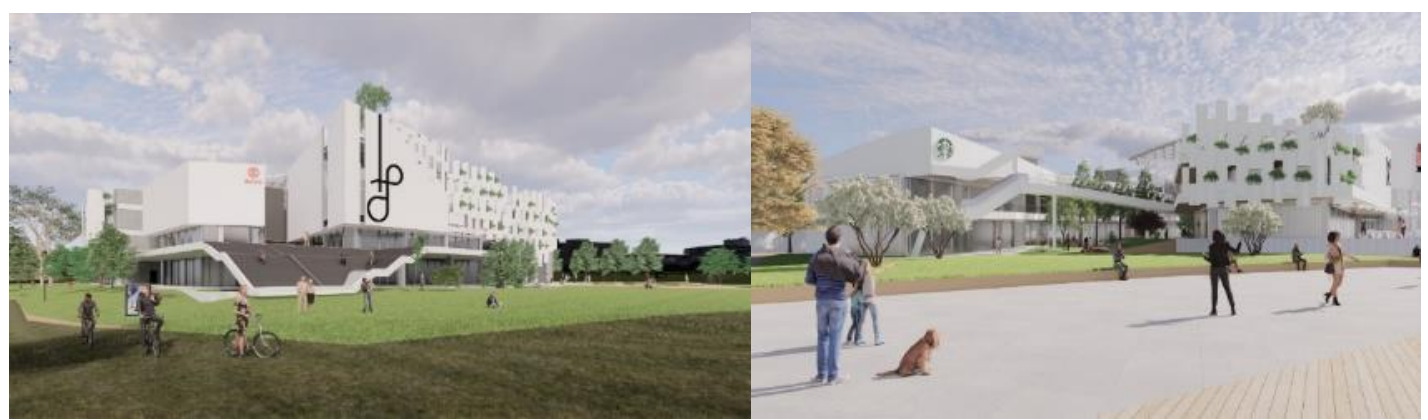

Gambar 16. Suasana pada Pintu Masuk Utama

Sumber: Penulis, 2021

\section{Kesimpulan}

Healthy Plaza Avenue merupakan sebuah pusat perbelanjaan atau shopping mall yang berlokasi di Kota Baru Parahyangan, di jalan Parahyangan dibangun di atas lahan seluas $31.300 \mathrm{~m} 2$. Bangunan ini direncanakan dengan tujuan pelengkap fasilitas Kota Baru Parahyangan, sebuah lingkungan hunian berskala kota di Barat kota Bandung. Metode perancangan Healthy Plaza Avenue dimulai dengan perumusan masalah, pengumpulan data, pengolahan data, proses desain, hingga produk rancangan. Konsep yang diterapkan adalah tema biofilik dengan prinsip Nature in the space dan Nature of the space, yang dapat dilihat pada penataan taman di atrium, penerapan wastewater 
management di area ruang luar, dan penerapan vertical garden pada fasad. Selain itu desain bangunan direncanakan semi terbuka untuk memperoleh sinar matahari secara optimal. Diharapkan penerapan prinsip Nature in the Space dan Nature of the Space pada Healthy Plaza Avenue dapat sejalan dengan visi Kota Baru Parahyangan yang memiliki visi sebagai kota hijau.

\section{Daftar Acuan}

Almused, A. (2011). Biophilic and Bioclimatic Architecture. Analytical Therapy for the Next Generation of Passive Sustainable Architecture. London : Springler-Verlag Lon-don Limited

Browning, W.D., Ryan, C.O., Clancy., J.O. (2014). 14 Patterns Of Biophilic Design. New York : Terrapin Bright green LCC

Priatman, J. (2012). Konsep Desain Biophilia Sebagai Dimensi Hijau Pada Arsitektur Empatik. Makalah Dipublikasikan Pada Seminar Nasional - Menuju Arsitektur Berempati Universitas Kristen Petra, Surabaya. Retrieved From https://repository.unsri.ac.id/8150/1/Isi_Kumpulan_Makalah_Menuju_Arsitektur_Berempati.

Savitri, R. (2018). Pusat Perbelanjaan Modern (Mall) Dengan Penekanan Ruang Terbuka Publik. Program Studi : Arsitektur, Fakultas Teknik, Universitas Tanjungpura, Pontianak Indonesia. Retrieved From https://jurnal.untan.ac.id/index.php/jmarsitek/article/view/30631/75676579730

Soderlund, J. (2019), The Emergence of Biophilic Design. Switzerland : Springer Nature Switzerland AG

Sumartono. (2015). Prinsip - Prinsip Desain Biofilik. PORDUCTUM Jurnal Desain Produk (Pengetahuan dan Perancangan Produk) 1 (1) : 15-21 